\title{
Interim FDG-PET in lymphoma, a questionable practice in hematology
}

\author{
Hugo J. A. Adams ${ }^{1}$ (D) Thomas C. Kwee ${ }^{2}$
}

Received: 5 July 2017 / Accepted: 16 July 2017 / Published online: 31 July 2017

(C) Springer-Verlag GmbH Germany 2017

Lymphoma is the sixth most frequently occurring malignancy in the Western world, accounting for $4.8 \%$ of all malignancies [1]. Lymphomas are treated with (immuno)chemotherapy or radiation therapy (RT), either as monotherapy or as combined modality treatment. Historically, treatment response evaluation was only applied after treatment, varied widely among institutions, and comprised several assessments such as the evaluation for the presence of B-symptoms, laboratory examinations, biopsies of residual masses, lymph nodes or bone marrow, liver and spleen assessment using laparotomy, and various imaging studies such as X-rays, gallium, and computed tomography (CT) scans [2]. In 1999 the International Workshop Criteria (IWC) [2] were published in order to standardize response criteria in non-Hodgkin's lymphoma. These criteria mainly relied on tumor shrinkage during therapy as assessed by CT by comparing the long-axis diameters before and after treatment [2]. In the first years of the millennium, ${ }^{18} \mathrm{~F}$-fluoro-2-deoxy-D-glucose positron emission tomography (FDG-PET) gradually entered the clinical arena, and several studies were published evaluating the prognostic value of FDG-PET scans after treatment. However, end-of-treatment FDG-PET scans were uniformly adopted in 2007 when

This Editorial Commentary refers to the article http://dx.doi.org/10.1007/ s00259-017-3758-5

Hugo J. A. Adams

h.j.a.adams@gmail.com

1 Department of Radiology and Nuclear Medicine, Deventer Ziekenhuis, Nico Bolkesteinlaan 75, 7416 SE Deventer, The Netherlands

2 Department of Radiology, Nuclear Medicine and Molecular Imaging, University Medical Center Groningen, University of Groningen, Groningen, The Netherlands integrated into the response criteria of the International Harmonization Project (IHP) [3, 4]. The 2014 Lugano criteria [5, 6] and 2016 refinement of the Lugano criteria [7] not only promote performing FDG-PET scans after treatment, but also during treatment, also known as interim FDG-PET. These examinations are also promoted by other guidelines such as the guidelines of the European Society of Oncology (ESMO) $[8,9]$ and the National Comprehensive Cancer Network (NCCN) $[10,11]$, and the value of these examinations are hyped at conference meetings [12-14]. Consequently, interim FDG-PET scanning is adopted worldwide at numerous institutions, and thousands of lymphoma patients undergo an interim FDG-PET evaluation every year.

In the present issue of the European Journal of Nuclear Medicine and Molecular Imaging, Lazarovici et al. [15] report the results of an important trial. Their study included 36 patients with primary mediastinal B-cell lymphoma (PMBCL) who underwent interim FDG-PET after four cycles of immunochemotherapy. Patients with positive interim FDGPET results according to non-specified criteria underwent histological restaging. Scans were retrospectively scored according to the Deauville criteria [6]. After four cycles of immunochemotherapy, 17 patients had positive interim FDG-PET results; two patients had a Deauville score of 2, one patient had a Deauville score of 3 , and 14 patients had a Deauville score of 4 . All these FDG-PET positive patients underwent histological restaging, 15 by means of surgical debulking, and two by means of CT-guided core biopsy. Histological examination revealed $16 / 17$ positive interim FDG-PET scans to be false-positive, resulting in a falsepositive rate of $94.1 \%$. False-positive results were caused by inflammatory necrosis/fibrosis in 15 cases and silicosis in one case. During a median follow-up of 48.5 months, 2/17 $(11.8 \%)$ of patients with positive interim FDG-PET results and $3 / 19(15.8 \%)$ of patients with interim FDG-PET negative 
results developed disease relapse. Lazarovici et al. [15] concluded that a positive interim FDG-PET result does not reflect active disease in the vast majority of cases. Furthermore, they concluded the relapse rate to be similar between interim FDGPET positive and negative patients, and that interim FDG-PET should be used with caution in PMBCL.

The study by Lazarovici et al. [15] is the first study that explicitly describes the false-positive rate in interim FDGPET positive PMBCL patients. However, several prior studies have assessed the false-positive rate of positive interim FDGPET results in aggressive non-Hodgkin's lymphoma using histological restaging as reference standard (Table 1). In 2010, a study by Moskowitz et al. [16] included 98 patients with advanced-stage aggressive non-Hodgkin's lymphoma (70 with diffuse large B-cell lymphoma [DLBCL] and 28 with PMBCL) who underwent interim FDG-PET after treatment with four cycles of R-CHOP. Patients with negative interim FDG-PET results received three additional cycles of ifosfamide, carboplatin, and etoposide (ICE), whereas patients with positive interim FDG-PET results underwent histological restaging. Patients with (false) positive interim FDG-PET results, but negative biopsies were treated equally as those with negative interim FDG-PET results, whereas patients with positive interim FDG-PET results and biopsies containing residual lymphomatous deposits were treated with intensified therapies consisting of three additional cycles of ICE, rituximab and high-dose therapy and autologous stem cell transplantation. After four cycles of R-CHOP, 97 patients underwent interim FDG-PET, which was positive in 38 cases (39.2\%). In line with the results of Lazarovici et al. [15], biopsy revealed a very high false-positive rate of 33/38 $(86.8 \%)$. Patients with positive interim FDG-PET, but negative histological restaging results had a similar outcome as those with negative interim FDG-PET results $(P=0.146)$. Moskowitz et al. [16] concluded that interim FDG-PET results do not predict outcome in patients with DLBCL/PMBCL. Another prospective study by Casasnovas et al. [17] included 98 patients with DLBCL. Interim FDG-PET was perfomed after four cycles of immunochemotherapy and was positive in $42 / 98$ (42.9\%) according to the IHP criteria. In $10 / 42$ (23.8\%) restaging biopsy was performed, which was falsepositive in $8 / 10(80 \%)$ of cases. A survival analysis on the prognostic value of false-positive interim FDG-PET results was not reported. Cox et al. [18] included 73 patients with DLBCL and 12 with PMBCL who underwent interim FDGPET after three cycles of R-CHOP or six cycles of R-MACOPB. $24 / 85$ (28.2\%) had positive interim FDG-PET results according to the IHP criteria, of whom seven underwent restaging

Table 1 Proportion of histopathologically proven false-positive interim FDG-PET results

\begin{tabular}{|c|c|c|c|c|c|c|c|}
\hline Study (year) & $\begin{array}{l}\text { Lymphoma } \\
\text { subtype }\end{array}$ & $\begin{array}{l}\text { Therapy before } \\
\text { FDG-PET acqui- } \\
\text { sition }\end{array}$ & $\begin{array}{l}\text { FDG-PET criteria } \\
\text { for positivity }\end{array}$ & $\begin{array}{l}\text { No. of interim } \\
\text { FDG-PET positive }\end{array}$ & $\begin{array}{l}\text { Proportion } \\
\text { of patients } \\
\text { biopsied } \\
(\%)\end{array}$ & $\begin{array}{l}\text { Proportion of } \\
\text { false-positive } \\
\text { results }(\%)\end{array}$ & $\begin{array}{l}\text { Histological findings of } \\
\text { false-positive cases }\end{array}$ \\
\hline $\begin{array}{l}\text { Lazarovici } \\
\text { et al. } \\
\text { (2017) } \\
{[15]}\end{array}$ & PMBCL & $\begin{array}{l}4 \times \text { R-ACVBP or } \\
4 \times \text { R-CHOP or } \\
4 \times \\
\text { R-COPADEM }\end{array}$ & Non-specified criteria & $\begin{array}{l}17 / 36(47.2 \%)(2 \times \\
\text { DS of } 2,1 \times \text { DS of } \\
3 \text { and } 14 \times \text { DS of } \\
4)^{*}\end{array}$ & $\begin{array}{l}17 / 17 \\
\quad(100 \%)\end{array}$ & $\begin{array}{l}16 / 17 \\
\quad(94.1 \%)\end{array}$ & $\begin{array}{l}\text { 15× inflammatory } \\
\text { necrosis/fibrosis } 1 \times \\
\text { silicosis }\end{array}$ \\
\hline $\begin{array}{l}\text { Schoder } \\
\quad \text { et al. } \\
\quad(2016) \\
{[19]}\end{array}$ & $\begin{array}{l}\text { DLBCL: } 51 \\
\text { PMBCL: } \\
13 \\
\text { FL grade } \\
\text { 3B: } 1\end{array}$ & $4 \times \mathrm{R}-\mathrm{CHOP}$ & DS 4-5 & $21 / 65(32.3 \%)$ & $\begin{array}{l}21 / 21 \\
\quad(100 \%)\end{array}$ & $\begin{array}{l}19 / 21 \\
\quad(90.5 \%)\end{array}$ & $19 \times$ inflammation \\
\hline $\begin{array}{l}\text { Cox et al. } \\
\quad(2012) \\
{[18]}\end{array}$ & $\begin{array}{l}\text { DLBCL: } 73 \\
\text { PMBCL: } \\
\quad 12\end{array}$ & $\begin{array}{c}3 \times \text { R-CHOP or } 6 \times \\
\text { R-MACOP-B }\end{array}$ & IHP & $24 / 85(28.2 \%)$ & $\begin{array}{l}7 / 24 \\
\quad(29.2 \%)\end{array}$ & $4 / 7(57.1 \%)$ & $\stackrel{4 \times}{\text { inflammation/reactive }}$ \\
\hline $\begin{array}{l}\text { Casasnovas } \\
\text { et al. } \\
(2011) \\
{[17]}\end{array}$ & DLBCL: 98 & $\begin{array}{l}4 \times \text { R-CHOP: } 52 \\
4 \times \text { R-ACVBP: } 50\end{array}$ & IHP & $42 / 98(42.9 \%)$ & $\begin{array}{l}10 / 42 \\
\quad(23.8 \%)\end{array}$ & $8 / 10(80 \%)$ & $\begin{array}{l}8 \times \text { "no evidence of } \\
\text { lymphoma" }\end{array}$ \\
\hline $\begin{array}{l}\text { Moskowitz } \\
\text { et al. } \\
\text { (2010) } \\
{[16]}\end{array}$ & DLBCL: 98 & $4 \times \mathrm{R}-\mathrm{CHOP}$ & $\begin{array}{l}\text { >local background } \\
\text { activity with } \\
\text { corresponding } \\
\text { abnormality at CT }\end{array}$ & $38 / 98(38.8 \%)$ & $\begin{array}{l}38 / 38 \\
\quad(100 \%)\end{array}$ & $\begin{array}{l}33 / 38 \\
\quad(86.8 \%)\end{array}$ & $33 \times$ inflammation \\
\hline
\end{tabular}

*A retrospective classification according the Deauville criteria was performed in this study

$A C V B P$, doxorubicin, cyclophosphamide, vindesine, bleomycin, and prednisone; $C H O P$ cyclophosphamide, doxorubicin, vincristine, and prednisone; COPADEM methotrexate, cyclophosphamide, vincristine, doxorubicin, and prednisone; $D L B C L$ diffuse large B-cell lymphoma; $D S$ Deauville score; $F L$ follicular lymphoma; IHP International Harmonization Project; $M A C O P-B$ methotrexate, leucovorin, doxorubicin, cyclophosphamide, vincristine, prednisone, bleomycin; $O S$ overall survival; $P F S$ progression-free survival; $P M B C L$ primary mediastinal B-cell lymphoma; $R$ rituximab 
biopsy. Four of seven $(57.1 \%)$ positive interim FDG-PET scans were considered false-positive, with biopsy showing inflammation only. Finally, a study by Schoder et al. [19] included 51 DLBCL, 13 PMBCL, and one follicular lymphoma grade 3B patients treated with four cycles of R-CHOP followed by an interim FDG-PET scan. Twenty-one of 65 $(32.3 \%)$ scans were classified positive with a Deauville score of 4 or 5 . All 21 patients underwent histological biopsies, which were false positive in 19/21(90.5\%) cases, all showing inflammation. In summary, the results of Lazarovici et al. [15] are in line with previous studies showing a strikingly high false-positive rate and a lack of prognostic value of positive interim FDG-PET results.

The non-specificity of FDG-PET scans is well known, with FDG accumulating in many different malignant and benign tumors, and non-neoplastic conditions, particularly (therapyinduced) inflammation. Laboratory studies have already shown that tumor-associated FDG-avidity is not only due to accumulation in tumor cells, but also due to a major proportion of FDG-avid accessory non-neoplastic cells, for example macrophages and granulocytes [20]. Particularly Hodgkin's lymphoma is well known for this phenomenon, because the neoplastic Reed-Sternberg cells comprise no more than 0.1$1.0 \%$ of the pathological substrate and the far majority consists of associated inflammatory neutrophils, macrophages, eosinophils, mast cells, histiocytes, macrophages, B-cells, and natural killer cells [21]. Laboratory studies indicate that soon after treatment initiation (as soon as 4-6 days), an increase in apoptotic and necrotic tumor cell is followed by an influx of inflammatory, FDG-consuming cells [20]. On the other hand, after treatment initiation, tumor FDG uptake declines rapidly as soon as after 1 day, and there is no difference in tumor FDG uptake between FDG-PET scans 20 days after treatment and after the entire regimen [22]. Therefore, interim FDG-PET does not reflect the dose-response relationship of anti-lymphoma treatments, as has been shown by aforementioned studies showing virtually all FDG uptake at interim PET to be caused by inflammation [15-19].

The fact that a positive interim FDG-PET may represent inflammation rather than viable lymphoma and that interim FDG-PET results have no prognostic value at all, have major clinical and scientific consequences. First, there is no justification to perform interim FDG-PET scans in routine clinical care. Note that the results can cause anxiety when the patient is incorrectly informed that the lymphoma is not responding well to treatment. Furthermore, it may erroneously cause the treating physician to alter treatment. Drawbacks such as the high costs and exposure to ionizing radiation associated with excessive FDG-PET imaging should also be considered. Moreover, considering the high false-positive rate, performing biopsies of residual FDG-avid lesions at interim FDG-PET will have low value and result in additional costs, anxiety, and risks. Second, interim FDG-PET results cannot be used for early assessment of the effectiveness of new therapies in ongoing or future therapeutic trials, and studies reporting interim FDG-PET results as outcome measure may not be valid. Finally, studies on treatment adaptation on the basis of interim FDG-PET results are likely in vain.

In conclusion, FDG-avidity at interim PET may represent (therapy-induced) inflammation rather than viable lymphoma and interim FDG-PET results may have no prognostic value. The hematology community has persistently overseen these findings and incorporated interim FDG-PET in guidelines on lymphoma, although the first results showing that interim FDG-PET may be infeasible were already published in 2010. Therefore, rectifying this misconception is needed and further research on interim FDG-PET is unlikely to be fruitful.

Author contributions Hugo J.A. Adams: study design, article writing, final approval of the manuscript.

Thomas C. Kwee: study design, article writing, final approval of the manuscript.

\section{Compliance with ethical standards}

Funding None.

Potential conflicts of interest None (all authors).

Ethical approval This article does not contain any studies with human participants or animals performed by any of the authors.

\section{References}

1. Siegel RL, Miller KD, Jemal A. Cancer statistics, 2017. CA Cancer J Clin. 2017;67:7-30. doi:10.3322/caac.21387.

2. Cheson BD, Horning SJ, Coiffier B, Shipp MA, Fisher RI, Connors $\mathrm{JM}$, et al. Report of an international workshop to standardize response criteria for non-Hodgkin's lymphomas. NCI sponsored international working group. J Clin Oncol. 1999;17:1244. doi:10. 1200/JCO.1999.17.4.1244.

3. Cheson BD, Pfistner B, Juweid ME, Gascoyne RD, Specht L, Horning SJ, et al. Revised response criteria for malignant lymphoma. J Clin Oncol. 2007;25:579-86. doi:10.1200/JCO.2006.09. 2403.

4. Juweid ME, Stroobants S, Hoekstra OS, Mottaghy FM, Dietlein M, Guermazi A, et al. Use of positron emission tomography for response assessment of lymphoma: consensus of the imaging Subcommittee of International Harmonization Project in lymphoma. J Clin Oncol. 2007;25:571-8. doi:10.1200/JCO.2006.08.2305.

5. Cheson BD, Fisher RI, Barrington SF, Cavalli F, Schwartz LH, Zucca E, et al. Recommendations for initial evaluation, staging, and response assessment of Hodgkin and non-Hodgkin lymphoma: the Lugano classification. J Clin Oncol. 2014;32:3059-68. doi:10. 1200/JCO.2013.54.8800.

6. Barrington SF, Mikhaeel NG, Kostakoglu L, Meignan M, Hutchings M, Mueller SP, et al. Role of imaging in the staging and response assessment of lymphoma: consensus of the international conference on malignant lymphomas imaging working group. J Clin Oncol Off J Am Soc Clin Oncol. 2014;32:3048-58. doi:10.1200/jco.2013.53.5229. 
7. Cheson BD, Ansell S, Schwartz L, Gordon LI, Advani R, Jacene $\mathrm{HA}$, et al. Refinement of the Lugano classification response criteria for lymphoma in the era of immunomodulatory therapy. Blood. 2016; doi:10.1182/blood-2016-05-718528.

8. Dreyling M, Ghielmini M, Rule S, Salles G, Vitolo U, Ladetto M, et al. Newly diagnosed and relapsed follicular lymphoma: ESMO clinical practice guidelines for diagnosis, treatment and follow-up. Ann Oncol. 2017; doi:10.1093/annonc/mdx020.

9. Eichenauer DA, Engert A, Andre M, Federico M, Illidge T, Hutchings M, et al. Hodgkin's lymphoma: ESMO clinical practice guidelines for diagnosis, treatment and follow-up. Ann Oncol. 2014;25(Suppl 3):iii70-5. doi:10.1093/annonc/mdu181.

10. Hoppe RT, Advani RH, Ai WZ, Ambinder RF, Aoun P, Bello CM, et al. Hodgkin lymphoma version 1.2017, NCCN clinical practice guidelines in oncology. J Natl Compr Cancer Netw JNCCN. 2017;15:608-38.

11. Zelenetz AD, Gordon LI, Wierda WG, Abramson JS, Advani RH, Andreadis CB, et al. Diffuse large B-cell lymphoma version 1.2016. J Natl Compr Cancer Netw. 2016;14:196-231.

12. Nanni C, Cottereau AS, Lopci E, Bodet-Milin C, Coronado M, Pro $\mathrm{B}$, et al. Report of the 6th international workshop on PET in lymphoma. Leuk Lymphoma. 2017:1-6. doi:10.1080/10428194.2017. 1298752.

13. Meignan M, Gallamini A, Haioun C, Barrington S, Itti E, Luminari $\mathrm{S}$, et al. Report on the 5th international workshop on positron emission tomography in lymphoma held in Menton, France, 19-20 September 2014. Leuk Lymphoma. 2015;56:1229-32. doi:10. 3109/10428194.2015.1029748.

14. Meignan M, Barrington S, Itti E, Gallamini A, Haioun C, Polliack A. Report on the 4th international workshop on positron emission tomography in lymphoma held in Menton, France, 3-5 October 2012. Leuk Lymphoma. 2014;55:31-7. doi:10.3109/10428194. 2013.802784.

15. Lazarovici J, Terroir M, Arfi-Rouche J, Michot JM, Mussot S, Florea V, et al. Poor predictive value of positive interim FDG-
PET/CT in primary mediastinal large B-cell lymphoma. Eur J Nucl Med Mol Imaging. 2017; doi:10.1007/s00259-017-3758-5.

16. Moskowitz CH, Schoder H, Teruya-Feldstein J, Sima C, Iasonos A, Portlock CS, et al. Risk-adapted dose-dense immunochemotherapy determined by interim FDG-PET in advanced-stage diffuse large Bcell lymphoma. J Clin Oncol Off J Am Soc Clin Oncol. 2010;28: 1896-903. doi:10.1200/jco.2009.26.5942.

17. Casasnovas RO, Meignan M, Berriolo-Riedinger A, Bardet S, Julian A, Thieblemont C, et al. SUVmax reduction improves early prognosis value of interim positron emission tomography scans in diffuse large B-cell lymphoma. Blood. 2011;118:37-43. doi:10. 1182/blood-2010-12-327767.

18. Cox MC, Ambrogi V, Lanni V, Cavalieri E, Pelliccia S, Scopinaro $\mathrm{F}$, et al. Use of interim [18F]fluorodeoxyglucose-positron emission tomography is not justified in diffuse large B-cell lymphoma during first-line immunochemotherapy. Leuk Lymphoma. 2012;53:263-9. doi:10.3109/10428194.2011.614704.

19. Schoder H, Zelenetz AD, Hamlin P, Gavane S, Horwitz S, Matasar $\mathrm{M}$, et al. Prospective study of 3'-Deoxy-3'-18F-Fluorothymidine PET for early interim response assessment in advanced-stage B-cell lymphoma. J Nucl Med. 2016;57:728-34. doi:10.2967/jnumed. 115.166769 .

20. Kubota R, Yamada S, Kubota K, Ishiwata K, Tamahashi N, Ido T. Intratumoral distribution of fluorine-18-fluorodeoxyglucose in vivo: high accumulation in macrophages and granulation tissues studied by microautoradiography. J Nucl Med. 1992;33:1972-80.

21. Pileri SA, Ascani S, Leoncini L, Sabattini E, Zinzani PL, Piccaluga PP, et al. Hodgkin's lymphoma: the pathologist's viewpoint. J Clin Pathol. 2002;55:162-76.

22. Yamane T, Daimaru O, Ito S, Yoshiya K, Nagata T, Ito S, et al. Decreased 18F-FDG uptake 1 day after initiation of chemotherapy for malignant lymphomas. J Nucl Med Off Publ Soc Nucl Med. 2004;45:1838-42. 